\title{
APRESENTAÇÃO DO DOSSIÊ "EDUCAÇÃ̃O POPULAR: desafios e perspectivas"
}

\author{
PRESENTATION OF THE DOSSIER "POPULAR EDUCATION: \\ challenges and prospects"
}

\section{PRESENTACIÓN DEL DOSSIER "EDUCACION POPULAR: desafíos y perspectivas"}

\author{
Arlete Ramos dos Santos \\ Ramofly Bicalho dos Santos ${ }^{2}$ \\ Claudio Pinto Nunes ${ }^{3}$
}

O Dossiê Educação Popular: desafios e perspectivas que compõe esta edição da RTPS - Revista Trabalho, Política e Sociedade nasce da necessidade de agregar um conjunto de estudos que são representativos da vasta experiência de pesquisa que tem se desenvolvido ao longo de anos sobre a educação, de modo geral, e sobre a educação popular, de modo mais específico.

Os temas abordados nos artigos que se agrupam neste dossiê contemplam significativa diversidade de temáticas acerca da educação popular, em diálogo com a educação do campo, em diversos territórios da América Latina.

Ressalta-se que a relevância histórica, social e científica de se trazer para os leitores as discussões da Educação Popular em diferentes aspectos e contextos contemplados no presente dossiê apresenta considerável pertinência e potencial de impacto na

\footnotetext{
${ }^{1}$ Doutora em Educação pela Universidade Federal de Minas Gerais (UFRM). Atua como docente da Universidade Estadual do Sudoeste da Bahia (UESB), onde integra o quadro docente do Programa de Pós-Graduação em Educação. É líder do Grupo de Estudos Movimentos Sociais, Diversidade e Educação do Campo e Cidade (GEPEMDECC/CNPq). ORCID: http://orcid.org/0000-0003-0217-3805 E-mail: arlerp@hotmail.com

${ }^{2}$ Doutor em Educação pela Universidade Estadual de Campinas (UNICAMP). Atua como docente na Universidade Federal Rural do Rio de Janeiro (UFRRJ), onde integra o quadro docente do Programa de Pós- Graduação em Educação Agrícola (PPGEA/UFRRJ) e do Programa de Pós-Graduação em Educação, Contextos Contemporâneos e Demandas Populares (PPGEduc/UFRRJ). ORCID: http://orcid.org/0000-0003-0571-6481 E-mail: ramofly@gmail.com

${ }^{3}$ Doutor em Educação pela Universidade Federal do Rio Grande do Norte (UFRN). Atua como Professor Titular da Universidade Estadual do Sudoeste da Bahia (UESB), onde integra o quadro docente do Programa de Pós-Graduação em Educação. É Líder do Grupo de Pesquisa Didática, Formação e Trabalho Docente (DIFORT/CNPq). ORCID: http://orcid.org/0000-0003-15146961 E-mail: claudionunesba@hotmail.com
} 
Área de Educação. As pesquisas e problematizações apresentadas dialogam com diversas correntes de pensamentos presentes na contemporaneidade educacional.

Durante séculos, a formação destinada às classes populares vinculou-se a um modelo "importado" de educação urbana. Os valores presentes no meio rural, quando comparados ao espaço urbano, eram tratados com descaso, subordinação e inferioridade. Num campo, estigmatizado e invisibilizado pela sociedade brasileira, multiplicam-se, cotidianamente, preconceitos e estereótipos.

Havia também nessa conjuntura o entendimento de que a educação popular, na interface com a educação do campo, contribuiria para uma série de lutas e embates políticos. Este foi o ponto de partida para inúmeras reflexões sociais, bem como também foi o momento em que tais reflexões se materializaram em espaços culturalmente próprios, detentores de tradições, especificidades e costumes singulares.

As pesquisas realizadas e apresentadas neste dossiê compreendem a complexidade dessas interfaces constituídas por lutas, organicidade, histórias, memórias, identidades e modos de vida. Nesta perspectiva, as políticas públicas permitem reafirmar e legitimar as lutas em prol da educação popular e são, portanto, necessárias para consolidação de um projeto político para o país.

Assim, emergem alguns questionamentos, tais como: que concepção de formação para cidadania se espera da educação popular? Qual o papel da escola para os estudantes do campo? Que saberes e aprendizagens são por eles valorizados? Qual a relação existente entre saberes teóricos e práticos da cultura? Que contribuições a educação popular apresenta no fortalecimento dos movimentos sociais e na pedagogia da alternância? Essas questões podem colaborar no aprofundamento teóricoprático acerca da emancipação humana e libertadora, além do respeito às diferenças e a igualdade historicamente silenciadas.

Do mesmo modo, estes questionamentos podem, ainda, contribuir na gestação de embriões de democratização, socialização de poder, superação dos desafios e afirmação de identidades essenciais nos periódicos da área de educação. Existe hoje nos espaços formais e informais da produção do conhecimento, uma urgente necessidade de intervenção, propondo reflexões que tenham por meta problematizar as dificuldades apresentadas no que concerne às questões teórico-metodológicas da educação popular, numa perspectiva crítica, dialógica e histórica do saber.

Assim, os artigos do dossiê Educação Popular, publicados na Revista Trabalho, Política e Sociedade, poderão contribuir com os debates acerca dos processos identitários ligados à visão de hegemonia na educação popular e do campo, reconfigurada pelos atores políticos nesses espaços de conflitos de ideias.

Os nove artigos que compõem este dossiê foram produzidos por professores pesquisadores e estudiosos da temática em tela, provenientes de diferentes universidades brasileiras e de outros países, são elas: Centro Universitário Dom Pedro II (UniDomPedro); Universidad Autónoma de Assunción (UAA), Paraguai; Universidade Estadual de Santa Cruz (UESC); Universidad Nacional Simón Rodríguez (UNESR), Venezuela; Universidad Nacional Experimental Rafael María Baralt (UNERMB), Venezuela; Universidade Federal Rural do Rio de Janeiro (UFRRJ), Brasil; Universidade Federal da Grande Dourado (UFGD), Brasil; Universidade Federal de Minas Gerais 
(UFMG), Brasil; Universidade Federal de São Carlos (UFSCar), Brasil; Universidade Federal de Goiás (UFG), Brasil; Universidade Estadual do Sudoeste da Bahia (UESB), Brasil; Universidade Federal do Pará (UFPA), Brasil; Universidade do Estado do Pará (UEPA), Brasil.

O primeiro artigo que compõe o dossiê tem como título "O trabalho na sociedade globalizada: uma reflexão da educação popular em Guiné Bissau e no Brasil", de autoria de Augusto Cardoso, Marizete Silva Souza e Siomara Castro Nery. O texto apresenta um debate teórico-crítico acerca da importância do trabalho na sociedade moderna no contexto do processo de globalização a partir de três aspectos: o trabalho como eixo central de governos; a formulação e implementação de ações sociais voltadas para o trabalho; e ações relacionadas à educação popular. Trata-se de uma abordagem de cunho qualitativo baseada em documentos e nos referenciais teóricos que explicam a complexidade das políticas públicas e sua gestão, bem como a natureza das organizações educativas. O objetivo é apresentar elementos que contribuam para a compreensão desta relação tríade, a partir de um comparativo entre a realidade brasileira e guineense, tendo em vista que o trabalho é a atividade por meio da qual o ser humano (re)produz sua própria existência.

O segundo artigo, intitulado "La educación popular en proceso de construcción del estado comunal en Venezuela", escrito por Samuel H. Carvajal Ruíz e Paulina E. Villasmil Socorro, tem como objetivo apresentar uma contribuição para o debate e refletir criticamente sobre aspectos teóricos e práticos da educação popular no contexto da construção do poder popular na Venezuela. Para tanto, os autores discutem algumas considerações teórico-conceituais sobre essa proposta educacional, e, do mesmo modo, também colocam na cena da discussão contribuições de pedagogos venezuelanos para o movimento. Finalmente, são registradas algumas experiências no desenvolvimento de sua práxis no trânsito complexo do modelo rentista-petróleo em vigor no país em questão, para uma sociedade democrática, participativa e líder, como fundamentos espirituais da emergente comunidade comunal.

O Terceiro artigo cujo título é "Educação especial em escolas do campo e indígenas: configurações em microcontextos brasileiros", tem como autores Allan Rocha Damasceno, Washington Cesar Shoiti Nozu e Michele Aparecida de Sá. Os resultados presentes no artigo, materialização das investigações dos autores, objetivam apresentar e problematizar as configurações da oferta dos serviços de Educação Especial em escolas do campo e indígenas, em decorrência da vigente Política Nacional de Educação Especial na perspectiva da Educação Inclusiva. Para tanto, por meio de revisão bibliográfica, são expostos dados de pesquisas empíricas que evidenciam nuances, similaridades, desdobramentos, ajustes e flexibilizações dos serviços de Educação Especial em escolas do campo e indígenas situadas em microcontextos dos seguintes estados brasileiros: Amapá, Mato Grosso do Sul, Pará e São Paulo. Nessa perspectiva, os autores buscaram elucidar, no contexto da prática, aspectos de gestão da inclusão de estudantes e de Professores de Apoio Educacional Especializado (PAEE) no âmbito da Educação do Campo e da Educação Escolar Indígena, de modo a sinalizar cenários, possibilidades e desafios de implementação dessa proposta política.

O quarto artigo, "A educação do campo no MST como ferramenta de construção da hegemonia", de autoria de Isabella de Mello Leite e Ramofly Bicalho, registra um 
apanhado histórico sobre como a temática da educação do campo foi ganhando notoriedade ao longo dos anos, em consonância com os conceitos gramscianos e como - Movimento dos Trabalhadores Rurais Sem Terra (MST) se movimentou para conquistar as políticas de Educação do Campo, a partir dos anos 90. Este resgate histórico se estende desde as primeiras leis até o momento atual, bem como destaca como eram pensadas as políticas que permeiam as práticas pedagógicas do/no campo. Problematiza também o modo como a educação se constitui imprescindível para o MST. A educação, nesse sentido, assume um significado político determinante para construção de outra hegemonia que oriente sua base militante.

O quinto artigo tem como título "Literatura de cordel e educação de jovens e adultos: de repente juntos no processo de letramento" e é de autoria de Gilvan dos Santos Sousa e Arlete Ramos dos Santos. Este artigo se originou de uma pesquisa de mestrado que teve como objetivo investigar o uso da Literatura de Cordel oriunda da educação popular como instrumento didático na Educação de Jovens e Adultos (EJA). O estudo buscou também averiguar a relevância dessa literatura como linguagem arteeducativa no processo de ensino-aprendizagem e a sua contribuição para a formação de alunos leitores, capazes de interagir com os debates realizados no espaço educativo. O estudo se valeu da aplicação de questionário e da técnica de Grupo Focal como instrumentos de coleta de dados. O campo da pesquisa - Escola Municipal Tobias Barreto - situa-se no município de Vitória da Conquista/BA. A pesquisa desenvolvida permitiu compreender que a Literatura de Cordel pode se tornar grande aliada nesse processo, por valorizar as culturas e experiências que permeiam o cotidiano destes alunos que, muitas vezes, passam despercebidas pelos sistemas educacionais.

O sexto artigo é escrito por Amone Inácia Alves e tem como título "Notícias sobre as escolas do campo em goiás: o que a imprensa goiana diz ou oculta sobre o fechamento das escolas". O artigo é fruto de uma pesquisa de cunho bibliográfico e apresenta como a imprensa goiana tem noticiado sobre o funcionamento das escolas do campo em Goiás, nos anos 2010. Há uma disputa hegemônica sobre como deve funcionar essas escolas, sendo que a imprensa assume um partido. Compreende-se que apesar da escola ser um dos instrumentos utilizados pelo campesinato para a transmissão de seus valores e tradições, ela tem sido maculada por um projeto de poder, de dominação econômica e de derrota dessa classe frente aos desmandos do capital. Ela tem sido pensada não a partir das suas especificidades, mas a partir de um projeto de cidade. A imprensa, no geral, quando apresenta notícias sobre as escolas, apoia-se nas seguintes categorias de análise: violência, precarização de contratos de professores, transporte escolar. Então é objeto desse texto mapear essas notícias, mostrando o retrato das escolas goianas, a partir da imprensa no Estado.

O sétimo artigo, "Curso Pré-Vestibular Universidade Para Todos: projeto de educação popular que prepara estudantes para o acesso ao nível superior", de Erivan Coqueiro Sousa e Cláudio Pinto Nunes, contextualiza o curso pré-vestibular Universidade Para Todos (UPT), projeto do governo do estado da Bahia, perante um movimento de educação popular. Para tanto se faz uma discussão sobre o percurso histórico dos cursos pré-vestibulares sociais que emergem, fortemente, a partir dos exames de admissão ao nível superior. A perspectiva é possibilitar melhores oportunidades de acesso à educação superior às pessoas com menores condições econômicas e advindas de escolas públicas. Os autores demonstram que a pedagogia 
presente nestes cursos não apenas atua perante o atendimento dos conteúdos exigidos nos processos seletivos, como também se desenvolve em consonância com a formação política, a conscientização e a reflexão crítica, em diálogo com conhecimentos políticos, históricos e culturais. Também ocorre uma explanação de um curso denominado de Pré-Vestibular Social que iniciou em 2002, como projeto de extensão universitária, no Campus XII, da UNEB, em Guanambi/BA. Este curso teve importância nas discussões do estado da Bahia para criar o UPT. É adotada, neste estudo, a perspectiva metodológica da revisão bibliográfica sobre o tema evidenciado. Há também a Investigação Qualitativa, com entrevista aberta, realizada com dois professores autores do PréVestibular Social, de Guanambi, e análise documental, a exemplo das leis e atas dos órgãos institucionais. Os resultados demonstram que o curso UPT é uma ação de caráter popular, que contribui para o acesso ao nível superior, que foi criado devido à diversas reivindicações sociais e que teve como base experiências predecessoras que obtiveram êxito.

O oitavo artigo tem como título "Educação popular e educação do campo na Amazônia: uma análise a partir dos movimentos sociais" e é de autoria de Salomão Mufarrej Hage e Sérgio Roberto Moraes Corrêa. O artigo reflete sobre Educação Popular e Educação do Campo, tomando como recorte a Amazônia, com foco nas lutas dos movimentos sociais. Os autores partiram da seguinte questão: o que as lutas dos movimentos sociais da Amazônia têm a contribuir para alargar a reflexão teórica e epistemológica e a ação política da Educação Popular e da Educação do Campo no Brasil, em particular na Amazônia? A partir desse questionamento, sugerem que a Amazônia é reveladora de múltiplas Amazônias, que expressa tanto uma rica e complexa sociobiodiversidade como um espaço social marcado por muitas contradições e conflitos de interesses que transpõem sua fronteira. Por isso ela ocupa um lugar de destaque e de relações de poder em escala global. No presente quadro histórico da sociedade brasileira, o governo Bolsonaro coloca a Amazônia brasileira na rota mais intensa da destruição, ao passo que um conjunto de diversos movimentos sociais e de povos e comunidades tradicionais vem lutando e resistindo em defesa de outros marcos civilizatórios. A conclusão é de que entender o que essas lutas apresentam para o revigoramento da Educação Popular e da Educação do Campo é fundamental para construir outros caminhos de interpretação da Amazônia e de sociabilidade.

O nono e último artigo do dossiê é escrito por Pedro Clei Sanches Macedo, intitulado "A formação de educadores do campo e o habitus professoral: reflexões sobre a teoria de Pierre Bourdieu como ferramenta sociológica de pesquisa". O estudo apresenta reflexões sobre a teoria de Pierre Bourdieu, buscando compreender a noção de habitus e habitus professoral como ferramenta sociológica da pesquisa. Neste estudo, foram identificados os principais elementos que contribuem para a realização de pesquisas que utilizam a teoria sociológica de Bourdieu como referencial metodológico na compreensão da prática pedagógica docente nas escolas do campo. O habitus se apresenta como estruturante e estruturador das práticas, a partir da percepção e da apreciação das experiências, numa relação dialética com os agentes, grupos e classes sociais. No exercício da profissão docente, Bourdieu apresenta o conceito de habitus professoral como parte do conjunto de elementos que estruturam a epistemologia da prática. No contexto das escolas do campo, trata-se do modo de ser e de agir do professor por meio de influências advindas da cultura escolar, 
compreendendo o conjunto de valores, crenças, concepções que orientam a prática dos educadores e educadoras do campo e que refletem as características da realidade em que constituiu sua formação.

Estes onze artigos do dossiê não pretendem esgotar a discussão sobre a Educação Popular. Ao contrário, o dossiê se propõe a trazer para o debate algumas temáticas com o objetivo de identificar lacunas a serem mais detidamente estudadas. Que seja potente este dossiê! 